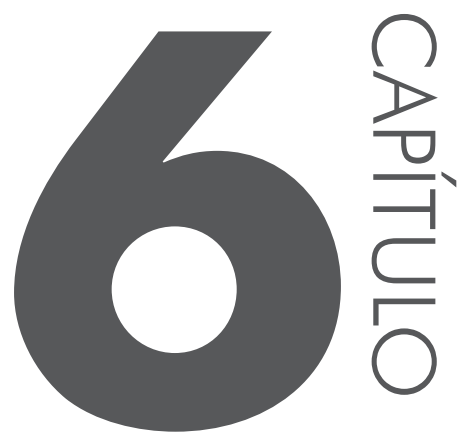

\title{
MORFOSSINTAXE E USO DOS PRONOMES PESSOAIS NA SINCRONIA E NA DIACRONIA DO PORTUGUÊS BRASILEIRO*
}

Charlotte Galves Universidade Estadual de Campinas

Juanito Avelar Universidade Estadual de Campinas

Dorothy Brito Universidade Federal Rural de Pernambuco

Danniel Carvalbo Universidade Federal da Bahia

Célia Lopes Universidade Federal do Rio de Janeiro

Leonardo Marcotulio Universidade Federal do Rio de Janeiro

* Este texto é uma versão revisada das comunicações apresentadas na mesa-redonda de mesmo título apresentado no VIIIo Congresso Internacional da Abralin. Baseia-se em pesquisas parcialmente financiadas pelas bolsas CNPq 305699/2010-5 e pelo auxílio Projeto Temático Fapesp 2012/06078-9. 


\subsection{INTRODUC̣ÃO}

A morfossintaxe dos pronomes é um dos aspectos da gramática do português brasileiro que mais aponta para uma diferenciação paramétrica forte dessa língua em relação ao português europeu e, de forma mais geral, às outras línguas românicas. Este capítulo discute alguns aspectos centrais dessa morfossintaxe e da variação no seu uso, tanto diacronicamente quanto sincronicamente: perda da diferenciação da segunda e terceira pessoa do singular no paradigma pronominal, interpretação de $1^{a}$ pessoa do sujeito nulo com $3^{\text {a }}$ pessoa do singular na flexão verbal, morfologia casual invariável dos pronomes fortes, reduplicação clítica sem preposição. As questões teóricas levantadas por esses fatos dizem respeito tanto à morfologia, composicionalidade e subespecificação de traços, quanto à sintaxe, natureza das categorias funcionais envolvidas, relação entre caso e concordância. Os fatos e as análises discutidos aqui são, portanto, cruciais para a compreensão das fixações paramétricas subjacentes à gramática do português brasileiro.

O texto é organizado da seguinte maneira: o item 6.2 descreve e analisa, numa ótica diacrônica, a variação na representação da segunda pessoa nas diversas funções sintáticas. No item 6.3, a possibilidade de uso da forma verbal de $3^{a}$ pessoa para expressão da $1^{a}$ pessoa no português afro-brasileiro é analisada no quadro da teoria de composição de traços. $\mathrm{O}$ item 6.4 discute a relação entre morfologia e caso no sistema pronominal do português brasileiro (PB). O item 6.5 fecha o capítulo com uma reflexão sobre os mecanismos subjacentes ao conjunto de fenômenos discutidos.

\subsection{OS REARRANJOS NO QUADRO PRONOMINAL: A REPRESENTAC̄̃̃O DA SEGUNDA PESSOA NOS SÉCULOS XIX E XX}

$\mathrm{Na}$ história do português, a inserção da nova forma gramaticalizada você no quadro da segunda pessoa do singular (2 SG), na posição de sujeito (nominativo), acarreta uma séria de reorganizações no que se refere às formas acusativas, dativas, oblíquas e genitivas. Como mostram diversos trabalhos sobre o tema (LOPES E CAVALCANTE, 2011; RUMEU, 2013; OLIVEIRA, 2014; SOUZA, 2014; entre outros), a implementação das formas do paradigma de você, que passam a coexistir e disputar espaço com as formas originais de 2 SG do paradigma de $t u$, não se dá da mesma forma em todos os dialetos do português. Nesse sentido, tentaremos comprovar que a reestruturação do quadro pronominal da 2 SG ora apresenta a maior conservação de formas morfológicas de $2 \mathrm{P}$ ora a incorporação de formas morfologicamente não-marcadas para o traço de pessoa, isto é, formas de $3^{\text {a }}$ pessoa.

Neste trabalho, o nosso objetivo é discutir como se deu a reorganização do quadro pronominal do português brasileiro a partir da entrada de você na 
gramática do PB. Para isso, partindo de um corpus constituído de cartas escritas no Rio de Janeiro, em fins do século XIX e na primeira metade do século XX (de 1870 a 1950 aproximadamente) $)^{1}$, observamos quais são as novas possibilidades combinatórias que foram se firmando ao longo do tempo de modo a analisar a correlação entre os pronomes de 2 SG utilizados na posição de sujeito e as formas empregadas como complemento verbal e como possessivo.

\subsubsection{A entrada de você no quadro da 2 SG na gramática do português brasileiro}

Os estudos que se dedicam à gramaticalização da forma de tratamento Vossa Mercê > você mostram que a inserção da forma pronominalizada você no quadro da 2 SG no português teria se dado mais facilmente pela posição de sujeito, num recorte temporal situado entre os séculos XIX e XX (cf. RUMEU, 2013; SOUZA, 2012 etc).

O trabalho de Souza (2012), com base em uma amostra de cartas familiares produzidas no Rio de Janeiro, acompanhou a emergência de você e o desuso gradativo de $t u$ na posição de sujeito ao longo de 100 anos (1870-1970). A autora mostrou que o pronome você era menos produtivo que a forma $t u \mathrm{em}$ 1870, mantendo-se assim até a virada do século XIX para o XX. A distribuição das duas formas se alterou a partir de então, com índices de frequência bastante equilibrados até 1930. De 1940 em diante, houve outra mudança com a inversão do comportamento de $t u$ e $v o c \hat{e}$ em relação à fase inicial. O uso de você tornou-se majoritário com o declínio do pronome $t u$ nas cartas em análise.

Durante o processo em questão, os valores das duas formas e as próprias relações sociais se modificaram. Num primeiro momento, tu e você não eram necessariamente formas variantes, uma vez que a primeira forma era empregada nas relações mais íntimas e a segunda ainda resguardava traços de cortesia de Vossa Mercê. Em uma segunda etapa, contudo, a forma você começou a ser empregada nos mesmos contextos funcionais de $t u$, sendo utilizada em contextos mais informais. Por fim, no período de 1940 a 1970, o uso de você suplantou a estratégia mais antiga com o seu espraiamento pelos contextos típicos de $t u$. Como uma estratégia de referência neutra, o pronome você tornou-se uma estratégia "coringa" para os novos papéis sociais das sociedades contemporâneas, principalmente em uma cidade cosmopolita como o Rio de Janeiro.

Partindo da proposta de Scherre et al. (2009), Lopes e Cavalcante (2011) defendem que, em função de tal processo, três subsistemas na posição de sujeito podem ser encontrados na história do português brasileiro: (i) subsistema 1: uso

1 Corpus Compartilhado Diacrônico de Cartas Pessoais - LABORHISTÓRICO, disponível em <http://www.letras.ufrj.br/laborhistorico>, LOPES, 2008). 
exclusivo ou majoritário de $t u$ (1); (ii) subsistema 2: uso exclusivo ou majoritário de você (2); e, por fim, (iii) subsistema 3: coexistência das formas tu e você (3):

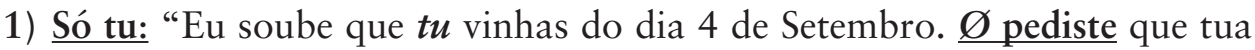
mãe foste te buscar" [24-09-1936]

2) Só você: Não fique triste, porque não mandei nenhuma foto para você. É que eu não tive tempo de escolher quais você poderia querer, nem tive tempo de pensar em quais que eu gostaria que você mandasse para mim." [08-05-1983]

3) Tu e você: "Nunca Você me respondeu sobre a casa de Petropolis, que resolveram? O que me toca, pedi que o Padre Jerony-mo ponha com o d'elle, até que

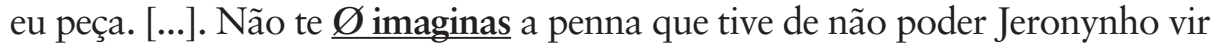
até aqui." [18-01-1920]

Levando em consideração os subsistemas apresentados por Lopes e Cavalcante (2011) para a posição de sujeito, o nosso intuito é observar os rearranjos ocasionados, a partir da entrada de você no quadro pronominal da $2 \mathrm{SG}$, nas demais posições sintáticas realizadas morfologicamente por formas pronominais. Em outras palavras, objetivamos verificar em que medida as formas o/a, lhe, preposição + você e seu, originais do paradigma de você, são implementadas em detrimento das formas originais de $2 \mathrm{P}$ te, preposição $+t i$, contigo e teu.

\subsubsection{A reorganização do quadro pronominal da 2 SG}

Apresentamos, nesta seção, os dados encontrados para as distintas realizações dos pronomes pessoais de acordo com a função gramatical exercida: formas acusativas (usadas para a função de complemento direto); formas dativas (formas preposicionadas ou não usadas para a função de complemento indireto); formas oblíquas (usadas unicamente para a função de complemento de preposição, diferenciando-se, portanto, das formas dativas por não admitirem cliticização); e formas genitivas (usadas para a função de modificador ou complemento do nome).

Os resultados serão apresentados da seguinte forma: em um primeiro momento, apresentamos a frequência geral das formas variantes de cada relação sintática encontradas na amostra de cartas cariocas produzidas de 1870 a 1950. Posteriormente, apresentamos os resultados em função da forma que aparece na posição de sujeito. Uma breve proposta de análise dos nossos dados é apresentada no item 6.2.3 deste trabalho.

\subsubsection{Acusativo}

Para a relação gramatical de complemento direto, o clítico te em (4) foi a variante acusativa mais produtiva com índices superiores a $90 \%$ do total dos dados. 
As demais formas ${ }^{2}$ não atingiram $10 \%$ de frequência de uso na amostra: você em (5) com $5 \%$, ola em (6) com apenas $1 \%$ e zero em (7) também com $1 \%$ :

4) "Eu te abençoo, e te acompanho em teus trabalhos pela salvação das almas n'este Valle de lagrimas N'este mundo feio e maó.” [23-06-1909]

5) "a luz de teu olhar e que ilumina a estrada por aonde sigo para encontrar voce que é a minha felicidade, se esta luz se apagar apagará tambem o meu nome da lista dos viventes sobre o mundo terrestre." [22-09-1936]

6) "Termino querida Irmã abraçando- $\underline{a}$ ternamente e enviando muitos carinhos e sou nos Santíssimos Corações deJesus e Maria sua irmã affetuosa” [16-02-1919]

7) Guimba esteve na Penha no Domingo, vai outra vez neste que vem, elle não te foi procurar na duvida de $\underline{\varnothing}$ encontrar. [1936]

O Gráfico 6.1 mostra como se dá a distribuição das formas de acusativo em função da variante de 2 SG que ocupa a posição de sujeito nas cartas em análise:

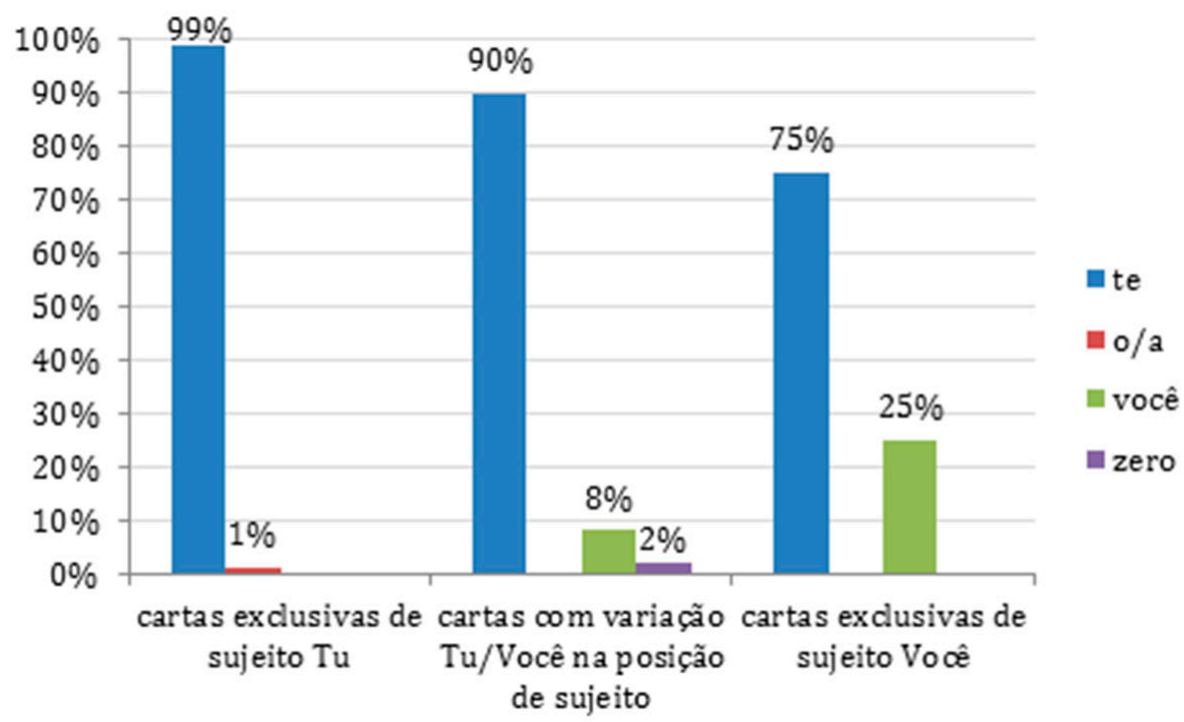

Gráfico 6.1 Formas acusativas em função do pronome sujeito.

A partir do Gráfico 6.1, observamos que em todas as cartas, independentemente do pronome que ocupa a posição de sujeito, a forma acusativa te é a mais produtiva, sendo praticamente categórica nas cartas exclusivas de sujeito $t u$. Nas

2 Embora não tenha sido localizado nesse conjunto de cartas, o clítico lhe também é uma das variantes dos complementos acusativos de 2 SG. 
cartas que admitem a variação entre $t u$ e $v o c e ̂$ na posição de sujeito, além de te, as formas você e zero como acusativo também são registradas, ainda que com baixa produtividade. Por fim, nas cartas exclusivas de sujeito você, a distribuição das formas de acusativo aponta para a utilização de te e você, com $75 \%$ e $25 \%$ do total de dados, respectivamente.

Como se pode observar pelos resultados apresentados, a relação gramatical de complemento direto parece se mostrar como um contexto de resistência à entrada das formas acusativas do paradigma de você. Vale destacar, nas cartas exclusivas de você como sujeito, a ausência das formas acusativas originais do paradigma de você: o/a. Retomaremos essa questão no item 6.2.3 deste trabalho.

\subsubsection{Dativo}

As formas dativas podem se manifestar morfologicamente por clíticos dativos ou por sintagmas preposicionais encabeçados pelas preposições $a$ ou para. Como foi observado no complemento acusativo, o clítico te em (8) se mostrou como a forma mais produtiva, atingindo $90 \%$ do total de ocorrências. Em termos cronológicos, os clíticos te e lhe foram as formas mais produtivas nas últimas décadas do século XIX (1870-1899) (76\% e 17\%, respectivamente). A partir da primeira década do século XX, houve a diminuição do uso de the em (9) com índices abaixo de $10 \%$ nas décadas subsequentes. O dativo te passa a concorrer, a partir dos anos 1910-1920, com as outras estratégias dativas, principalmente, com o zero que apresenta um acréscimo significativo nesse período. Dentre as formas que disputam espaço com te, na primeira metade do século $\mathrm{XX}$, registramos os seguintes índices, em ordem decrescente de produtividade: zero em (10) com $15 \%$, lhe com $9 \%$, preposição + você em (11-12) com 7\% e, por fim, preposição $+t i$ em (13-14) com apenas 3\%:

8) "O Tito vai bem, hoje vai te escrever, ele gostou muito do Rio, papai levou eles até Botafogo para ver a avenida beira-mar.” [18-08-1907]

9) "Eu não apressei-me em escrever lhe falando no seu novo despacho porque a falar a verdade não fiquei contente com o lugar que lhe deram [...].” [14-11-1874]

10) ["Ontem e hoje tivemos bom tempo; sol a serrano. O frio é somente pela noite e mais pela madrugada. Receba com seus irmãos muitos abraços e saudades nossas. Seu pai e amigo, Julio. ] ps. Quer que ø mande seu sobretudo argentino ou o outro? [8-06-1917]

11) "Diga ao Edgard que recebi a carta dele que não respondo porque a resposta é a que agora dou a você.." [13-05-1917]

12) "Você querendo me favorecer, compra para você e só será meu quando eu te pagar." [12-02-1909] 
13) “[...] diz-se que Você é quem influe para que a revolução continue, enfim attribuem a ti tudo, nunca vi maior injustiça...” [25-04-1894]

14) "São 11 horas preciso dormir, se não fosse isso seria capaz de ficar a noite toda escrevendo para ti, dizendo tudo quanto sinto por ti..." [0203-1937]

Considerando o pronome que ocupa a posição de sujeito, vejamos como se distribuem as estratégias de dativo:

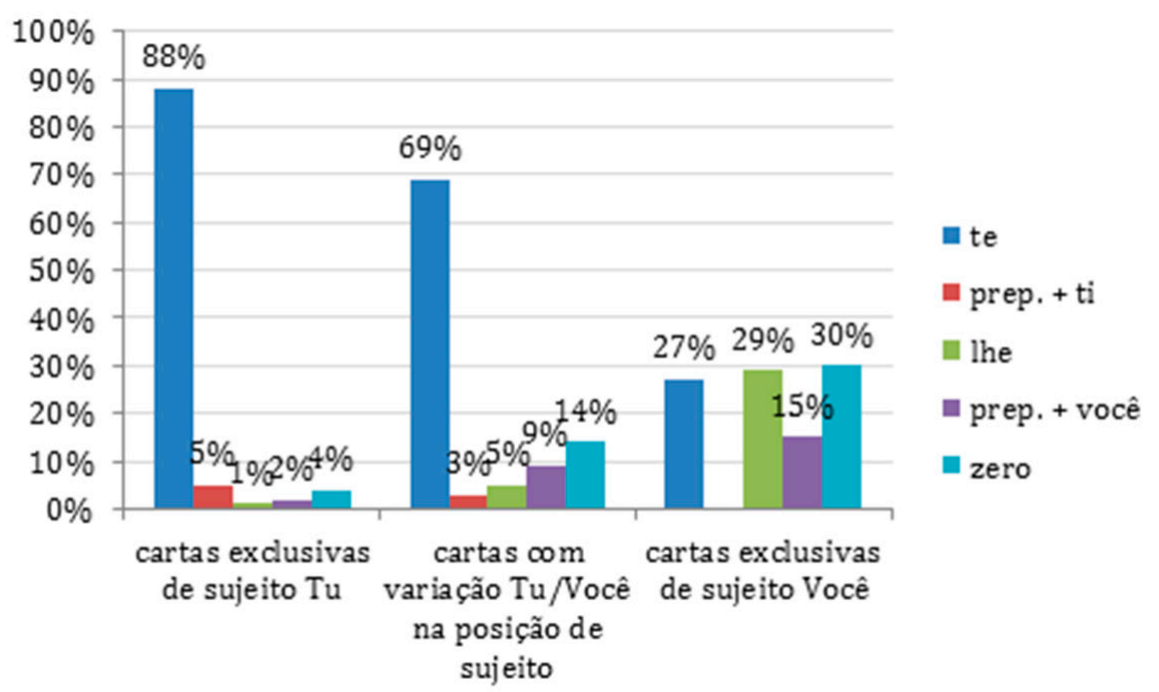

Gráfico 6.2 Formas dativas em função do pronome sujeito.

A partir da análise do Gráfico 6.2, observamos que o clítico dativo te se mostra como mais produtivo nas cartas exclusivas de sujeito $t u$, com índice de $88 \%$ do total de dados, e nas cartas em que coexistem as formas tu e você como sujeito, com $69 \%$ de ocorrências, ainda que nestas últimas já se faz notar com maior nitidez a presença de formas originais do paradigma de você, como preposição + você e lhe, com $9 \%$ e $5 \%$ de ocorrências, respectivamente. Por fim, em relação às cartas que apresentam como sujeito unicamente o pronome você, a distribuição das formas dativas parece estar mais equilibrada. Diferentemente do que ocorre com o acusativo, o clítico dativo te não apresenta os maiores índices de frequência ( $27 \%$ ), sendo o zero e o clítico dativo original de você - a forma lhe - as estratégias mais produtivas, com $30 \%$ e $29 \%$, respectivamente.

Chama a atenção, nesse cenário, que a relação gramatical de complemento indireto se mostra ligeiramente mais propícia à incorporação de formas do pa- 
radigma de você, se comparada com as formas acusativas, ainda que o clítico original de 2 SG te ainda mostre resistência.

\subsubsection{Oblíquo}

Quanto às relações oblíquas, em que os pronomes funcionam como complementos de preposições, diferentemente do observado até então, as formas do paradigma de você em (15) foram mais produtivas que as do paradigma de tu em (16):

15) “eu então pensava só em você o quanto tens sofrido por minha causa somente por amar-me” [26-09-1936]

16) "tu mereces muito mais minha flor, sem ti morrerei" [26-09-1936]

O Gráfico 6.3 evidencia essa diferença de comportamento na correlação entre as formas oblíquas e o pronome empregado na posição de sujeito:

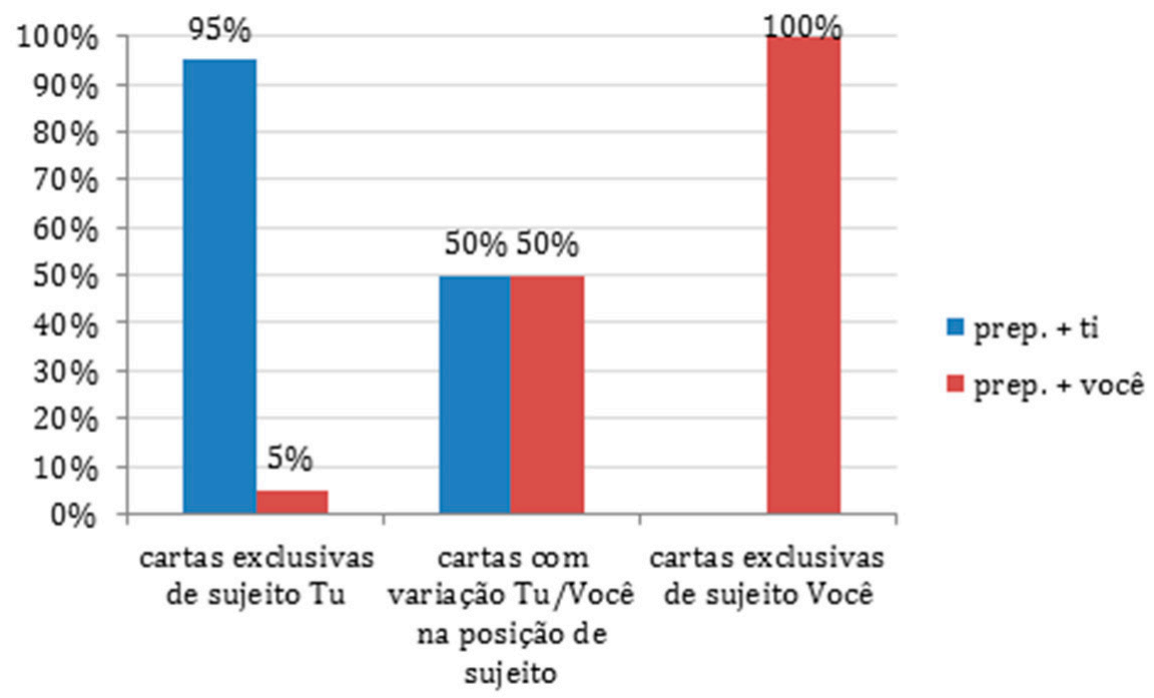

Gráfico 6.3 Formas oblíquas em função do pronome sujeito.

Como podemos ver no Gráfico 6.3, o sintagma preposicional preposição + ti é praticamente categórico, com $95 \%$ das ocorrências, nas cartas exclusivas de sujeito $t u$. Nas cartas em que $t u$ e você coexistem como sujeito, as duas estratégias - preposição + ti e preposição + você - são encontradas ao mesmo pé de igualdade. Por fim, diferentemente das posições de complemento direto e complemento indireto, as relações oblíquas presentes nas cartas exclusivas de sujeito você são categoricamente realizadas pela forma original do paradigma de você: preposição + você. 


\subsubsection{Genitivo}

As formas genitivas encontradas na amostra analisada foram teu em (17) e seu em (18) com predomínio expressivo do possessivo original de 2 SG (teu). Tal possessivo se manteve mais produtivo, com $84 \%$ nos dados de fins do século XIX e $79 \%$ no primeiro quartel do século XX:

17) "eu te adoro te amo até a morte sou tua só e tu é meu só o meu coração e teu e o teu coração é meu. a Chininha é todinha tua até a morte” [2904-1908]

18) "Foi com muito prazer que recebi sua carta de 3 de Janeiro próximo passado principalmente por trazer com ela a notícia do seu restabelecimento”. [12-02-1873]

A seguir, no Gráfico 6.4, vemos a distribuição entre teu e seu em função do pronome que ocupa a posição de sujeito da carta:

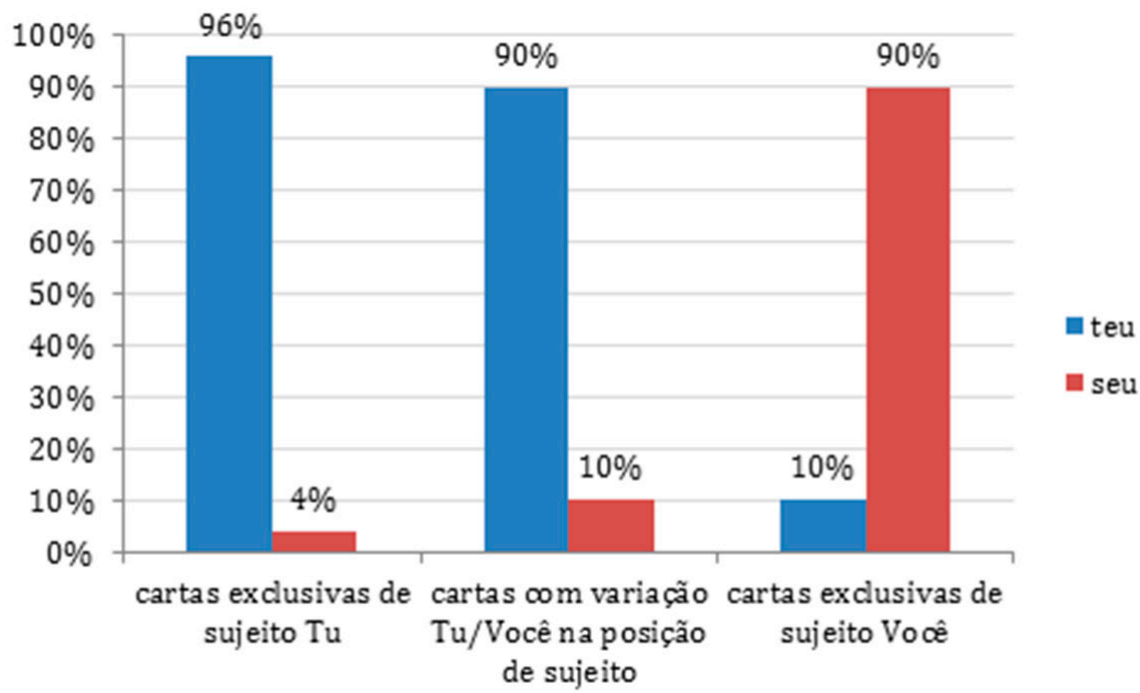

Gráfico 6.4 Formas genitivas em função do pronome sujeito.

O possessivo teu predomina tanto nas cartas que são exclusivas de sujeito $t u$, quanto nas cartas em que as formas de tratamento tu e você coexistem, com $96 \%$ e $90 \%$ do total de dados, respectivamente. Já nas cartas exclusivas de sujeito você, com exceção das relações oblíquas, em que verificamos $100 \%$ da estratégia preposição + você, o comportamento dos possessivos aponta para uma maior inserção da forma original do paradigma de você, o possessivo seu, com índice de $90 \%$ das ocorrências. 


\subsection{3 $O$ que dizem os dados sobre os rearranjos no quadro da 2P na gramática do PB?}

Uma vez apresentados os comportamentos dos pronomes complemento e possessivo, separadamente, tratemos de como os dados podem iluminar os rearranjos no quadro da 2 SG na gramática do português brasileiro, aqui representado por uma amostra de cartas escritas no Rio de Janeiro em fins do século XIX e meados do século XX.

Para tanto, de modo a facilitar a visualização das reorganizações operadas, agrupamos todas as estratégias possíveis em função do paradigma: formas pertencentes ao paradigma de tu e formas pertencentes ao paradigma de você. Partimos da hipótese de que a implementação das formas originais do paradigma de você não se deu da mesma forma em todas as subclasses de pronomes. Estudos anteriores (cf. LOPES; CAVALCANTE, 2011; RUMEU, 2013; SOUZA, 2012, entre outros) demonstraram o avanço das formas originais do paradigma de você como nominativo (sujeito) e complemento oblíquo, principalmente, nos idos de 1930. Nas funções de complemento acusativo e dativo, entretanto, as formas do paradigma de $t u$ mantiveram-se recorrentes com destaque para o clítico te nas duas funções (OLIVEIRA, 2014 e SOUZA, 2014). Na função genitiva, como demonstrado em 6.2.2.4, observou-se um favorecimento para a forma possessiva seu nas cartas com você na posição de sujeito.

O Gráfico 6.5 dá um panorama das funções de complemento e possessivo, correlacionando as formas do paradigma de você ao pronome empregado na posição de sujeito das cartas:

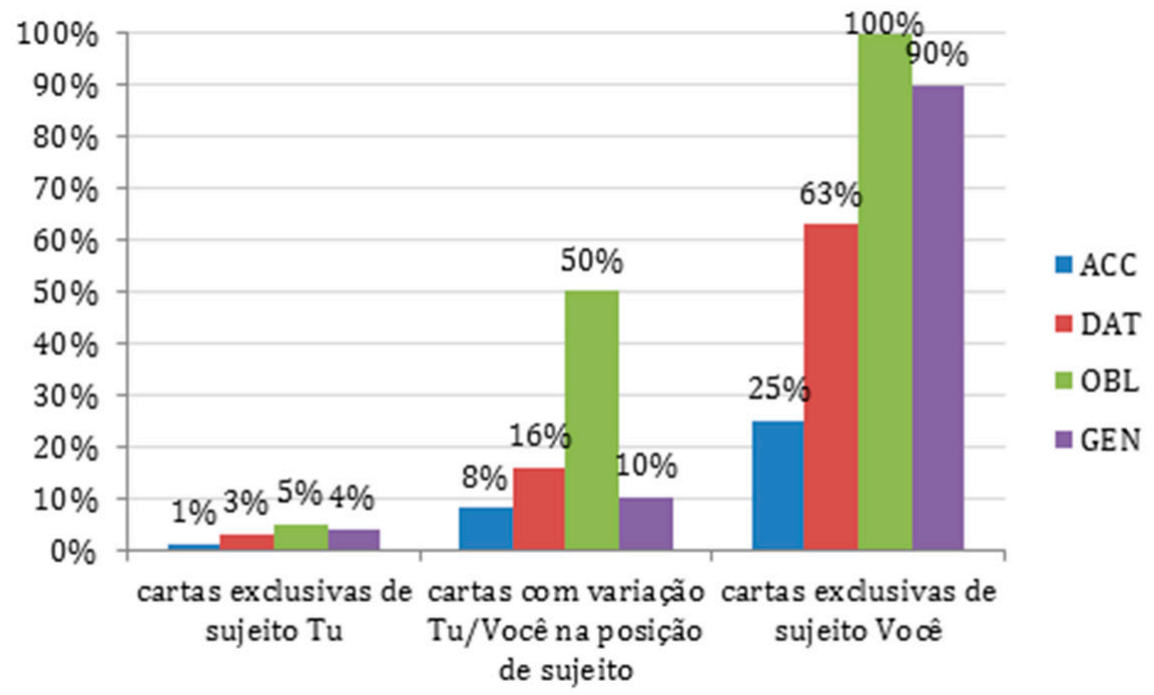

Gráfico 6.5 Formas pronominais de você em função do pronome sujeito. 
Analisando, em particular, as cartas com uso exclusivo de você na posição de sujeito, observamos uma maior implementação de pronomes do paradigma de você nas relações oblíquas, com $100 \%$ (preposição + você), seguidas pelas relações expressas pelo possessivo (seu), com $90 \%$ dos dados. O dativo (lhe, a/para você) aparece em terceiro lugar com $63 \%$ das ocorrências. As relações de complemento direto se mostraram menos propícias à implementação das formas de você, com apenas $25 \%$ de ocorrências. Nessa função, como discutido em 6.3.1, o clítico te reina absoluto, uma vez que os clíticos acusativos de você (o/a) tiveram apenas $1 \%$ de frequência no cômputo geral dos dados.

A partir desses resultados, como explicar as reestruturações no quadro das formas acusativas, dativas e genitivas e a manutenção total somente das formas oblíquas originais do paradigma de você? Como explicar a não implementação do clítico acusativo o/a e a manutenção da forma te, original do paradigma de $t u$ ?

Como no sistema em que tu e você coexistem como sujeito as formas relativas a $t u$ são possíveis, consideraremos, para esta discussão, somente o sistema em que você é a única forma de tratamento empregada. Comecemos por sintetizar os resultados obtidos:

Quadro 6.1 Rearranjos no quadro pronominal da 2P com sujeito você

\begin{tabular}{|c|c|c|c|}
\hline & nas & Formas coexistentes & \multirow{2}{*}{ Novo paradigma } \\
\hline \multicolumn{2}{|c|}{ do paradigma de você } & do paradigma de tu & \\
\hline \multirow{2}{*}{ ACC } & $o / a$ & te & te \\
\hline & você & - & você \\
\hline \multirow{2}{*}{ DAT } & Ihe & te & Ihe | te \\
\hline & prep. + você & - & prep. + você \\
\hline OBL & prep. + você & - & prep. + você \\
\hline GEN & seu & teu & seu | teu \\
\hline
\end{tabular}

Na relação gramatical de complemento direto, das formas acusativas próprias do paradigma de $v o c \hat{e}-o / a$ e $v o c \hat{e}$-, o novo paradigma emergente no século $\mathrm{XX}$, evidenciado aqui em cartas de sujeito exclusivo você, apresenta somente a forma você em coexistência com o clítico acusativo te, do paradigma de $t u$. Quanto ao complemento indireto, todas as formas dativas originais do paradigma de você - lhe, preposição + você - são mantidas e convivem com o clítico dativo te. Em relação ao oblíquo, a única forma original preposição + você é mantida. Por fim, no que se refere ao genitivo, o possessivo correspondente ao paradigma de você-seu - coexiste com o possessivo teu. 
Os resultados mostram o encaixamento nas posições de complemento e de possessivo de uma mudança que ocorre inicialmente na posição de sujeito. Aparentemente vemos um paradigma misto em relação às diferentes relações gramaticais e subclasses de pronome: formas do paradigma de você coexistem com formas do paradigma de $t u$. Esses resultados apontam para o fato de que algumas formas pronominais da 2 SG original $t u$ ainda resistem.

Uma vez que as formas originais do paradigma de você não são marcadas morfologicamente para o traço de pessoa, como explicar a interação entre você e formas pronominais de complemento e de possessivo do paradigma de $t u$ ? Em outros termos, como explicar a relação entre a forma que ocupa a posição de sujeito e as demais posições sintáticas?

De modo a oferecer uma explicação inicial para os rearranjos ocorridos, trabalhamos com a hipótese de que a inserção de você na posição de sujeito apresenta consequências para todo o paradigma pronominal (acusativo, dativo, oblíquo e genitivo). Assim, argumentamos que as diferenças nas posições de complemento e possessivo são governadas por uma mudança gramatical que afeta a posição de sujeito: como a forma você passa a ser especificada para o traço de pessoa (2P), a preferência se dará por formas de complemento e possessivo que também sejam especificadas para o mesmo traço de $2 \mathrm{P}$. As formas de $3^{\mathrm{a}}$ pessoa, por sua vez, por não serem especificadas morfologicamente para o traço de pessoa, serão preteridas.

A partir da hipótese levantada, justificamos a permanência das formas de oblíquo encontradas: preposição + você. No que se refere às demais relações gramaticais, a manutenção das formas originais de $t u$ como acusativo (te), dativo (te) e genitivo (teu) se justifica pela ausência do traço de pessoa nas formas originais do paradigma de você, como as formas de $3^{a}$ pessoa de acusativo o/a, dativo lhe e genitivo seu:

Quadro 6.2 Reorganização no quadro pronominal da 2P: formas de você e de tu

\begin{tabular}{|c|c|c|c|c|}
\hline \multicolumn{3}{|c|}{ Formas originais de você } & \multicolumn{2}{|c|}{ Formas mantidas de tu } \\
\hline $\mathrm{ACC}$ & $\circ / a$ & & $\mathrm{Te}$ & \\
\hline DAT & Ihe & {$[\mathrm{OP}]^{3}$} & $\mathrm{Te}$ & {$[2 \mathrm{P}]$} \\
\hline GEN & seu & & Teu & \\
\hline
\end{tabular}

Uma distinção, no entanto, precisa ser apontada. Diferentemente do que ocorre com as formas acusativas o/a, nem a forma dativa lhe nem a forma genitiva seu são descartadas. Argumentamos que, ainda que não seja especificado para

Representamos como [0P] as formas de $3^{\text {a }}$ pessoa, por não serem especificadas morfologicamente para o traço de pessoa. 
o traço de pessoa, o clítico dativo lhe apresenta a propriedade de abrigar um traço [+humano], o que justifica a sua manutenção no paradigma em formação, ao lado de te e preposição + você, ainda que com produtividade restrita.

Por fim, caberia explicar, no entanto, o comportamento dos genitivos. Por um lado, em termos de composicionalidade ${ }^{4}$, a forma de genitivo seu se assemelha às formas de acusativo o/a, já que não é marcada formalmente para o traço de pessoa; por outro, os resultados mostram que, além de o genitivo seu não ter sido descartado, também apresenta uma alta produtividade de uso, como mostra o Quadro 6.3:

Quadro 6.3 Composicionalidade e produtividade das formas pronominais do paradigma de você.

\begin{tabular}{cccc}
\hline Formas pronominais & & Composicionalidade & Produtividade \\
\hline ACC & $\circ / a$ & {$[O P ;$-humano $]$} & nula \\
DAT & lhe & {$[O P ;$ thumano $]$} & média/restrita \\
GEN & seu & {$[O P ;$ possuidor $]$} & alta \\
\hline
\end{tabular}

O comportamento do genitivo parece se diferenciar do comportamento dos demais pronomes: formas acusativas e dativas do paradigma de você tendem a ter implementação nula ou limitada; por outro lado, a forma genitiva seu mostra uma alta taxa de produtividade.

Em função dos limites deste trabalho, não discutiremos essa questão aqui. No entanto, indicamos como um possível encaminhamento o fato de o possessivo apresentar, em sua composicionalidade interna, um traço que aqui chamamos de [possuidor] que pressupõe, necessariamente, a presença de um traço [+humano]. Além disso, outras questões podem estar em jogo nesse caso, como a reorganização particular sofrida pelo sistema de possessivos no português brasileiro, tendo o possessivo seu se especializado para a referência da 2 SG em virtude da emergência de de-possessivos para as demais pessoas, como dele/dela para a $3 \mathrm{SG}$, deles/ delas para a 3 PL e de vocês para a 2 PL (cf. PERINI, 1985; 2010).

\subsubsection{Considerações finais}

Como pôde ser visto nessa breve exposição, a entrada de você como pronome-sujeito na gramática do português brasileiro gera uma série de rearranjos

4 Estamos tratando, aqui, da noção de composicionalidade de uma maneira informal, fazendo referência ao repertório de traços que compõem os pronomes. Para um tratamento mais preciso do conceito, ver item 6.3.3. 
nas demais subclasses pronominais, não tendo a implementação de formas acusativas, dativas, oblíquas e genitivas operado de igual maneira. A proposta que esboçamos aqui se direciona para o fato de haver uma restrição gramatical ligada aos traços de $2 \mathrm{P}$ e/ou [+humano]: somente as formas que apresentam ao menos um dos traços mencionados passam a compor o paradigma de você; nos demais casos, observamos a manutenção das formas originais do paradigma de $t u$. Assim, observamos, da menor para a maior implementação, as seguintes formas do paradigma de você: acusativo < dativo < genitivo < oblíquo.

\subsection{PRONOMES NULOS E REFERÊNCIA NO PORTUGUÊS AFRO-BRASILEIRO}

\subsubsection{Apresentação}

Este trabalho tem como objetivo descrever como é estabelecida a referencialidade em contextos de concordância de primeira pessoa do singular não marcada no $\mathrm{PB}$, estabelecendo uma comparação entre o sistema referencial de $1^{\mathrm{a}}$ pessoa da comunidade de Helvécia - BA e o da comunidade de Muquém - AL.

Algumas relações precisam ser feitas entre os processos de surgimento das comunidades de Helvécia e de Muquém. Primeiramente, do ponto de vista geográfico, salvo as devidas proporções, ambas as localidades podem ser consideradas de difícil acesso, estando Helvécia, uma comunidade rural afro-brasileira cuja economia é essencialmente agrícola, no extremo sul do estado da Bahia, no município de Nova Viçosa, enquanto Muquém está localizada a $5 \mathrm{~km}$ da cidade de União dos Palmares, em Alagoas, o que poderia sugerir um processo semelhante de desenvolvimento das línguas faladas em ambas as localidades.

Ambas as comunidades foram constituídas majoritariamente por escravos (cativos ou libertos), mas estabeleceram contatos linguísticos diferenciados: Helvécia tinha uma maioria de senhores estrangeira, enquanto em Muquém conviviam, provavelmente, brancos, índios e negros nascidos em terras brasileiras. Apesar de terem a mesma idade nas datas em que as entrevistas foram coletadas, uma diferença de aproximadamente duas décadas separa o nascimento das nossas duas informantes, o que, conjuntamente às particularidades constitutivas de cada comunidade, pode determinar diferenças acentuadas nas variedades do PB adquiridas por HV-13 e F3.

\subsubsection{Sobre os dados}

Selecionamos, para análise, contextos de realização da primeira pessoa do singular na posição de sujeito, quer como pronome pleno, quer como pronome nulo, pro: 
HV-13 (Helvécia) $)^{5}$

19) ieu gosto é de roça, num gosto de comércio não.

20) Eu passô com minha fia no fazado mais marido dela.

21) Fui nascido ali na roça, ficô criô lá na roça, até dobrô, casô, tudo na roça.

22) Não fuma, não bebe, só vinho, bebida minha, num fuma nada.

23) esses bebida assim manso ieu pego, mas esse babo ieu num bebe não.

24) eu num pode sabê, que eu tava pequeno, né?

25) Só vejo falá nome, mas num conhece.

26) se eu dô o senhô marcriaçon, eles me dão um côro chateado.

27) ieu acho qu'é cas'd'idade, porque ieu mesmo num conhece não, meu senhô.

F3 (Muquém) ${ }^{6}$

28) eu nu sô da famia - mai eu entrei na famia - sô da famia - n'é - passei-passei sessenta e dois ano casada - depoi o marido morreu: fiquei n'é?

29) Cheguei aqui cum doze ano.

30) Eu vim de fora.

31) e - eu posso fazê loiça não - mia fia - eu - é um sacrifício pa me levantá - eu i fazê loiça.

32) Nunca saí - só vô dá uma viage - pá num votá mais.

33) - Pa cidade tem no - ôinbo - tem um ôinbo - qu'eu num sei que ôinbo que é não.

Podemos observar, nos dados de HV-13, uma oscilação na realização do pronome de primeira pessoa do singular, mesmo em contextos em que ele não pode ser sintaticamente recuperado, ou seja, com verbos que não apresentam a flexão correspondente à primeira pessoa do singular (cf. (22)). Já os dados de F3 demonstram o padrão de realização do pronome pleno na posição de sujeito, assim como de pro referencial, identificado no português brasileiro em geral, ou seja, pro como sujeito de um verbo que apresenta a morfologia de pessoa (lembrando que estamos tratando apenas da $1^{\text {a }}$ pessoa do singular).

5 Todos os dados referentes ao Português afro-brasileiro foram extraídos do inquérito HV-13, componente do banco de dados do Projeto Vertentes do Português Popular do Estado da Bahia.

6 Todos os dados referentes à caracterização da comunidade de Muquém, assim como os dados extraídos do inquérito de F3, são componentes do Projeto O Conhecimento Linguístico e Sociocultural da Comunidade Quilombola Muquém, União dos Palmares - Alagoas. 


\subsection{3 pro no PB e no português afro-brasileiro (PAB)}

No PB, temos o sujeito referencial nulo enfraquecido e o paradigma de flexão verbal de pessoa e número também enfraquecido (DUARTE, 1995). Segundo Lucchesi (2009), o PB também exibe processos de variação e mudança induzidos pelo contato entre línguas, mas em um grau mais leve do que o observado nas línguas crioulas de base lexical portuguesa da África.

Para o PAB, temos um quadro similar ao apresentado pelo $\mathrm{PB}$, mas por motivações diferentes: segundo Lucchesi (2009), as comunidades rurais afro-brasileiras foram afetadas diretamente pelo contato maciço e abrupto entre línguas na sua formação, o que impedia a realização do sujeito nulo por conta do enfraquecimento da flexão verbal influenciada por esse contato. A possibilidade de ocorrência do pro referencial surge posteriormente, a partir do contato entre essas comunidades e falantes do $\mathrm{PB}$, o que resulta em um padrão diferenciado de ocorrência do sujeito nulo, como pode ser constatado nos dados de HV-13. Já a contemporânea não realização do sujeito nulo no PB culto deve-se à reorganização que o paradigma pronominal dessa língua vem sofrendo após a inserção dos pronomes você e a gente.

\subsubsection{Sobre concordância e composição de traços}

Béjar (2003) propõe uma teoria de traços para concordância com bases minimalistas, preenchendo uma lacuna na empreitada gerativista. A análise se baseia em uma perspectiva para traços formais onde $\varphi$ codifica as propriedades nominais que tipicamente entram no processo de concordância: pessoa, número e gênero. Entretanto, tais propriedades são insuficientes para capturar exigências sintáticas de uma teoria de concordância baseada apenas em traços. Assim, a autora assume com Harley; Ritter (2002) que pronomes obedecem a uma hierarquia interna, que é responsável por sua sistematização. As tradicionais categorias pessoa e número são centrais na teoria desenvolvida por Béjar, porém, a abreviação tradicional de traços- $\varphi$ como um conjunto cristalizado de traços que compõem um elemento R(eferencial) é inviável, uma vez que não captura as relações que um elemento $\mathrm{R}$ pode ter no sistema computacional, sendo alguns desses traços ausentes por razões independentes.

Harley; Ritter (2002), ao proporem uma decomposição dos tradicionais traços- $\varphi$, são coerentes com a variabilidade encontrada inter-linguisticamente. Uma teoria nessas premissas implica subespecificação no sentido de que um dado elemento $\mathrm{R}$ pode não apresentar todos os traços, apesar de tê-los disponíveis em seu inventário. Isso, na verdade, é similar à proposta de Cardinaletti; Starke (1999) no sentido de que deficiência ${ }^{7}$ (ausência de um dado traço por acarretamento ${ }^{8}$ ) é

Do inglês deficiency (cf. CARDINALETTI \& STARKE, 1999).

8 A definição de acarretamento pode ser conferida no item 6.3.5.1. 
responsável pela distribucionalidade do pronome. Aqui, defenderemos um modelo fundido de deficiência, como definido em (34):

34) Um pronome é deficiente se carece pelo menos de um traço.

Os reflexos de tal deficiência são sentidos sintaticamente, ou seja, têm implicações em como o mecanismo de concordância funcionará, uma vez que um pronome deficiente pode exitosamente entrar em uma relação de concordância, i.e., a derivação envolvendo um pronome deficiente e, ao mesmo tempo, um verbo totalmente especificado, converge, mesmo não satisfazendo certas condições para concordância (match nos termos de CHOMSKY, 1999), como será mostrado adiante.

\subsubsection{Composicionalidade de traços: pessoa}

A geometria de Harley; Ritter (2002) permite a possibilidade de subespecificação (parcial e/ou total) de um dado sistema pronominal. Sistematicamente, subespecificação codifica contraste: uma subespecificação total quando da ausência do nó [PARTICIPANT], por exemplo, resulta na terceira pessoa, enquanto subespecificação relativa pode resultar na segunda pessoa quando o nó [PARTICIPANT] tem uma interpretação default na ausência de mais nós dependentes. Consequentemente, o traço [SPEAKER] é normalmente dependente do traço [PARTICIPANT], resultando na primeira pessoa ${ }^{9}$.

Béjar (2003) introduz um novo traço à geometria de Harley; Ritter (2002), a saber, $[\varpi]$. $\varpi$ é um nó intermediário entre a raiz do elemento referencial e o nó [PARTICIPANT]. Este é também um rótulo para a categoria pessoa. Segundo a autora, $[\varpi]$ é empiricamente necessário. Por exemplo, sem ele, não participantes são obrigatoriamente subespecificados exceto pelo traço [INDIVIDUATION], e, talvez, pelo traço raiz $[\mathrm{R}]^{10}$. A introdução deste traço é também motivada pelo fato de a subespecificação de traços para terceira pessoa poder ser o ponto de variação, uma vez que, apesar de alguns pronomes de terceira pessoa serem totalmente subespecificados, há pronomes de terceira pessoa com subespecificação parcial, os quais podem atuar como interventores ${ }^{11}$. Béjar (2003) afirma que a

9 Béjar nota que, em algumas línguas, a primeira pessoa é a default, sendo representada por [PARTICIPANT [ADDRESSEE]].

10 Assumimos $\mathrm{R}$ aqui como uma representação para pronome.

${ }^{11}$ Béjar (2003) propõe uma teoria enriquecida de traços para lidar com certas condições de concordância sensíveis ao contexto, quando um alvo que não é o potencial (ou seja, um interventor) pode entrar numa relação sonda-alvo. Por exemplo, em georgiano, "a verb cross-references the person feature of its object, unless the object is $3^{\text {rd }}$ person, in which case the person feature of the subject is cross-referenced" ( "um verbo remete ao traço pessoa de seu objeto, a não ser que o objeto seja de terceira pessoa, caso em que o verbo remete ao traço pessoa do sujeito " (BÉJAR, 2003, p.4). 
inserção do traço $[\varpi]$ é necessária como uma camada representativa, já que alguns traços categoriais devem ser incluídos dentro do nó [PARTICIPANT].

Como Béjar (2003) aponta, em algumas línguas esta decomposição de pessoa como proposta por Harley; Ritter (2002) não é suficiente para codificar alguns traços que são necessários para definir certos nominais. Por exemplo, [DEFINITE] e [ANIMATE] são acarretados por [PARTICIPANT] em línguas como húngaro e algonquiano, respectivamente (BÉJAR, 2003). Estas categorias, alternativamente, podem ser requeridas pelo nó [PARTICIPANT]. Portanto, [ø] rotularia os traços que podem ser capturados entre R e [PARTICIPANT], assumindo a representação em (35).

\section{5) SPEAKER $>$ PARTICIPANT $>\{$ DEICTIC $>$ DEFINITE $>$ SPECIFIC $>\ldots>$ D $=$ $\varpi\}>R$}

Entretanto, sugerimos que [๘] não codifica, mas, estruturalmente, deve dominar tais traços. Isto se dá porque alguns traços assumidos por Béjar (2003) como sendo codificados por $[\varpi]$ podem ou não estar presentes na configuração. Se eles fossem concebidos dentro de [๘], isso feriria as condições de acarretamento. Portanto, se traços como [DEFINITE] ou [SPECIFIC] estivessem localizados dentro de $[\varpi]$, isto é, codificados por $[\varpi]$, seria impossível ter estes traços como distintivos em um pronome arbitrário como você, em (36).

36) Você pensa que tá fazendo a coisa certa, mas no fim você não está. "Alguém pensa estar fazendo a coisa certa, mas no fim esse alguém não está" " 2 sg pensa estar fazendo a coisa certa, mas no fim 2 sg não está”

Nesse caso, o acarretamento de traços abaixo de [D] é responsável pela leitura arbitrária: na ausência de traços como [DEFINITE], você carece de uma leitura definida, que requer dêixis. Desse modo, pessoa, como uma categoria, permanece intacta enquanto traços como [SPECIFIC] ou [DEFINITE] desempenham o papel da arbitrariedade referencial. Assim, assumimos com Béjar (2003) que o nó [ø] é uma variável que codifica outros elementos que podem ser necessários para contraste de pessoa.

Por isso, assumiremos a estrutura em (37) como sendo a possível configuração para R. (37) é a entrada lexical da categoria pessoa de um dado pronome que entra na derivação, engatilhando todos os mecanismos sintáticos necessários para que ele alcance PF.

37) $[\mathrm{R}[\varpi[$ Participant[Speaker][Addressee $]][\mathrm{D}[$ Specific[Definite $]]]]$

Assim, a representação dos pronomes em PB de acordo com sua composicionalidade de traços gera o seguinte resultado: $[\varpi]$ é responsável sozinho pela 
diferenciação de primeira, segunda e terceira pessoas, como esperado. Portanto, a especificação de traços relevantes para os pronomes aqui é a seguinte:

1 pessoa:

a. Definido: [R[๘[PART[SPEAKER]][D[SPECIFIC][DEFINITE]]]]

b. Arbitrário: [R[๘[PART[SPEAKER]][D]]]

\section{2 pessoa:}

a. Definido: [R[๘[PART[ADDR]][D[SPECIFIC][DEFINITE]]]]

b. Arbitrário: [R[๘[PART[ADDR]][D]]]

\section{$3^{\mathrm{a}}$ pessoa: $[\mathrm{R}[\varpi[\mathrm{D}[\ldots]]]]$}

As reticências para a configuração da terceira pessoa indicam que os traços dominados por [D] podem ou não estar presentes na composição, dependendo da estrutura informacional do pronome.

Voltando ao fenômeno discutido neste trabalho, pronomes foneticamente nulos teriam, na sintaxe, as mesmas propriedades dos demais pronomes, uma vez que o material fonético estará disponível apenas após a sintaxe. Assim, um pro com referência de $1^{a}$ pessoa singular teria a mesma estrutura do pronome de $1^{\text {a }}$ pessoa do singular foneticamente realizado $(e u)$. Portanto, em (38), extraído dos dados de HV-13, teríamos a representação do pronome foneticamente nulo:

38) Num [R[๘[PART[SPEAKER]][D[SPECIFIC][DEFINITE]]]] teve porção de fio não!

Como já fora discutido em trabalhos anteriores (BÉJAR, 2003, 2008; CARVALHO, 2008, 2011), essa decomposição de traços exige alguns ajustes no processo de concordância (Agree).

A operação Agree (CHOMSKY, 1998) apaga traços formais ilegíveis durante o mecanismo de valoração de traços formais de um elemento nominal (alvo) por traços formais do mesmo tipo de um núcleo funcional (sonda). Havendo correspondência entre esses traços, os traços formais ilegíveis são apagados. Agree é regulada por condições para match, como, por exemplo, a identidade de traços ${ }^{12}$.

12 Matching is the relation that holds of a probe $\mathrm{P}$ and a goal G. Not every matching pair includes Agree. To do so, G must (at least) be in the domain $\mathrm{D}(\mathrm{P})$ of $\mathrm{P}$ and satisfy locality conditions. The simplest assumptions for the probe-goal system are:

(i) Matching is feature identity

(ii) $\mathrm{D}(\mathrm{P})$ is the sister of $\mathrm{P}$

(iii) Locality reduces to 'closest c-command'.

(CHOMSKY, 1998, p. 122) 
Uma teoria de concordância baseada em subespecificação de traços implica algumas adaptações no tradicional conceito de Agree (CHOMSKY, 1998; 1999). A teoria de concordância proposta por Béjar (2003) mostra que tais condições para concordância são perfeitamente compatíveis com a noção de subespecificação. De acordo com a teoria de traços apresentada aqui, uma sonda com um traço $[\mathrm{F}]$ pode facilmente ter em seu domínio um alvo com os traços [F[G]]. A questão que surge é se haverá compatibilidade entre estes traços já que não há identidade entre eles, como previsto pelas condições para match. A solução seria assumir que tais condições possam ser repensadas nas bases de acarretamento, expostas abaixo:

\subsubsection{Acarretamento}

Dados dois elementos A e B, respectivamente, numa ordem hierárquica, a presença de $\mathrm{B}$ requer a presença de $\mathrm{A}$.

Como apontado por Béjar (2003), o critério para match pode ser estabelecido em termos da presença do traço $[\mathrm{F}]$ na sonda. Assim, $[\mathrm{F}]$ encontraria correspondência em $[F[G]]$, pois $[F]$ é um subconjunto de $[F[G]]$. Isto prediz, por exemplo, que [PARTICIPANT] teria correspondência com um elemento [PARTICIPANT[SPEAKER]]. Carvalho (2008) assume com Béjar (2003) que a intersecção de traços da sonda e do alvo é suficiente para estabelecer correspondência.

Value aqui é concebido como o compartilhamento do rótulo que o traço carrega (FRAMPTON; GUTMANN, 2000). Assim, podemos assumir que value equivale à cópia de traços do alvo pela sonda, assumindo a generalização em (39) (cf. BÉJAR, 2003, p. 65).

39) Goal values Probe iff features of Goal entail features of Probe.

Uma vez que match é satisfeito apenas pela raiz da sonda e value precisa de um alvo no mínimo tão especificado quanto a sonda, a operação Agree é bem-sucedida. Portanto, é necessário apenas um $[\varpi]$ não-interpretável para uma sonda ser valorada. Isto se dá, pois o conjunto de condições que satisfazem value deve ser um subconjunto daquelas que satisfazem match.

Sobre os dados propostos para análise neste trabalho e, como já mencionado, a diferença entre os pronomes pessoais que são foneticamente realizados e os que não o são vai depender da disponibilidade dos itens morfológicos disponíveis pós-sintaticamente ${ }^{13}$.

13 Não estamos necessariamente nos remetendo à Morfologia Distribuída (MD) (HALLE; MARANTZ, 1993). O que propomos, a partir de uma teoria de traços, é que a sintaxe trabalhe apenas com traços abstratos. A seleção morfológica destes elementos seria realizada ou não a partir de algum mecanismo que só está disponível pós-sintaticamente. Basicamente, a diferença entre nossa proposta e a MD se dá no fato de que para nós apenas o conteúdo morfológico dos itens lexicais seria de responsabilidade de PF, enquanto todas as outras operações (inclusive 
Dessa forma, dados como os apresentados abaixo em (40) tem como estrutura de traços dos pares sonda-alvo as apresentadas nas tabelas abaixo. Esses dados representam os padrões de realização da primeira pessoa do singular nos dados: pronome foneticamente realizado de $1^{\text {a }}$ pessoa do singular com verbo morfologicamente realizado na $1^{\mathrm{a}}$ pessoa $(40 \mathrm{a})$; pronome foneticamente não realizado de $1^{a}$ pessoa do singular com verbo morfologicamente realizado na $1^{a}$ pessoa (40b); pronome foneticamente realizado de $1^{a}$ pessoa do singular com verbo morfologicamente realizado na $3^{\mathrm{a}}$ pessoa $(40 \mathrm{c})$; pronome foneticamente não realizado de $1^{\mathrm{a}}$ pessoa do singular com verbo morfologicamente realizado na $3^{\mathrm{a}}$ pessoa $(40 \mathrm{~d})$.

40) a. Eu sei não: mia fia

b. Cheguei aqui cum doze ano

c. Eu passô com minha fia no fazado mais marido dela.

d. Num teve porção de fio não

Tabela 6.1 Agree dos traços de pessoa com pares sonda-alvo (40a)

\begin{tabular}{cc}
\hline Sonda (sei) & Alvo (ev) \\
\hline & {$[\varpi]$} \\
& [participant] \\
[speaker] & \\
{$[\cup \varpi]$} & Agree é bem- \\
[uparticipant] & -sucedido \\
[uspeaker] & \\
\hline
\end{tabular}

Tabela 6.2 Agree dos traços de pessoa com pares sonda-alvo (40b)

\begin{tabular}{cc}
\hline Sonda(cheguei) & Alvo (-) \\
\hline & {$[\varpi]$} \\
& [participant] \\
& [speaker] \\
{$[\cup \varpi]$} & Agree é bem- \\
{$[$ uparticipant] } & -sucedido \\
[uspeaker] & \\
\hline
\end{tabular}

aquelas lexicais), não. Em outras palavras, mantemos o léxico pré-sintático e é este léxico que disponibiliza todos os traços necessários para a derivação. Portanto, assumimos que o Princípio da Interpretação Plena (Principle of Full Interpretation) exige que nenhum traço semântico ou formal esteja presente em PF, e traços fonológicos e ilegíveis não estejam presentes em LF para que a derivação convirja. Isto é facilmente satisfeito pela assunção de que traços fonológicos são instâncias de PF apenas e não participam da derivação (cf. CARVALHO, 2008, p. 21). 
Tabela 6.3 Agree dos traços de pessoa com pares sonda-alvo (40c)

\begin{tabular}{cc}
\hline Sonda (passô) & Alvo (eu) \\
\hline & {$[\varpi]$} \\
& [participant] \\
& [speaker] \\
\hline$[u \varpi]$ & Agree é bem- \\
& -sucedido \\
\hline
\end{tabular}

Tabela 6.4 Agree dos traços de pessoa com pares sonda-alvo (40d)

\begin{tabular}{cc}
\hline Sonda (feve) & Alvo (-) \\
\hline & {$[\varpi]$} \\
& {$[$ [participant] } \\
& [speaker] \\
\hline$[\cup \varpi]$ & Agree é bem- \\
& -sucedido \\
\hline
\end{tabular}

Chamamos atenção para o fato de esses padrões de concordância valerem para os dados encontrados no vernáculo de outras variedades do português, como podemos verificar nos dados abaixo, do português brasileiro vernacular falado em Maceió (41) e do português europeu vernacular falado em Lisboa (42).

41) Quando ${ }_{[\mathrm{R}[\text { [I[PART[SPEAKER]][D[SPECIFIC][DEFINITE] ]]] }}$ penso em fazer supermercado, [R[I[PART[SPEAKER]][D[SPECIFIC][DEFINITE] ]]] entro em pânico ${ }^{14}$.

42) Não [R[n[PART[SPEAKER]][D[SPECIFIC][DEFINITE]]]] caí dentro do poço, mas todos os dias [R[n[PART[SPEAKER]][D[SPECIFIC][DEFINITE]]]], passo os torniquetes e $[$ [R[IPART[SPEAKER]][D[SPECIFIC][DEFINITE] ] $]]$ entro num universo paralelo ${ }^{15}$.

\subsubsection{Algumas palavras finais}

Retomando a discussão acerca do contato, com base na análise apresentada acima, podemos assumir que diferentes gramáticas podem gerar diferentes spell-outs fonéticos, mas a estrutura gramatical destas diferentes variedades do português se mantém. Nosso argumento parte do princípio de que a gramática estabelecida em contextos de contato linguístico ou não, nessas variedades, oferece um único padrão de concordância, cuja variação se dá em termos de subespecificação dos traços dos elementos participantes da operação Agree.

14 Dado de introspecção, uma vez que somos falantes nativos do PB nascidos em Maceió, Alagoas. 15 Dado extraído do endereço eletrônico <http://www.blogger.com/profile/04133903811482645121>. 
Constatamos, assim, diferenças nos padrões de concordância nas gramáticas de F3 e HV-13: em F3 encontramos, quanto à realização do pro referencial de $1^{\text {a }}$ pessoa, uma gramática muito semelhante àquela encontrada no $\mathrm{PB}$ contemporâneo. Ribeiro (2009) afirma que "falar de um enfraquecimento da morfologia verbal só seria adequado para uma parcela da população, como [...] as retratadas em estudos diacrônicos com base na norma culta; para a população representada por HV-19, simplesmente não há morfologia verbal, exceto para a $1^{\mathrm{a}}$ pessoa do singular (embora variável)" (idem, p. 96). Com a possível conexão entre morfologia flexional e ocorrência do pro referencial, podemos supor, então, que talvez a gramática de F3 já apresente influências de um contato com o PB culto - talvez aquele utilizado pelos senhores de escravos dos seus pais e avós. Já HV-13, por ser de Helvécia e sua contemporânea, apresenta, em sua gramática, um comportamento do pro referencial semelhante ao de HV-19, com todas as especificidades discutidas ao longo deste trabalho.

\subsection{TRAC̣O DE CASO E REALIZAC̣ÃO MORFOLÓGICA NO SISTEMA PRONOMINAL DO PB}

\subsubsection{Introdução}

No português brasileiro (PB), formas pronominais nominativas (italicizadas nos exemplos em (a) de (43)-(45) a seguir) são largamente empregadas na posição de objeto (como nos casos em (b)) em lugar de formas pronominais acusativas (italicizadas em (c)).

43) a. Eu vi a Maria.

b. A Maria viu eu.

c. A Maria me viu.

44) a. Você/Tu conhece a Maria.

b. A Maria conhece vocêltu.

c. A Maria lhelte conhece.

45) a. Ele conhece a Maria.

b. A Maria conhece ele.

c. A Maria o conhece.

Seguindo Avelar \& Galves (2011), vamos argumentar que o licenciamento de pronomes nominativos em posição acusativa pode ser formalmente captado se considerarmos que os sintagmas nominais do PB (aí incluídos os pronomes pessoais) podem entrar na derivação sintática sem portar um traço de Caso [K]. Em linhas gerais, iremos explorar a ideia de que as expressões nominais do $\mathrm{PB}$ 
podem ser [+K], quando dispõem de um traço de Caso, ou [-K], quando não dispõem de um traço de Caso. Especificamente no que tange aos pronomes pessoais, os itens que entram na derivação como [-K] são realizadas em sua forma default, que consiste morfologicamente no nominativo. Nesses termos, os itens eu, vocêl tu e ele apresentados em (b) nos exemplos de (43)-(45) acima são a realização de pronomes $[-\mathrm{K}]$, enquanto os itens $m e$, lhe/te e $o$ consistem na versão $[+\mathrm{K}] \mathrm{de}$ pronomes do mesmo tipo., como indicado em (46) a seguir.
46) a. A Maria viu eu ${ }^{[-K]}$.
a'. A Maria $\mathrm{me}^{[+\mathrm{K}]}$ viu.
b. A Maria conhece você $\hat{e}^{[-\mathrm{K}]} / \mathrm{tu}^{[-\mathrm{K}]}$.
b'. A Maria te $\mathrm{t}^{[+\mathrm{K}]}$ conhece.
c. A Maria conhece ele $e^{[-K]}$.
c'. A Maria $\mathrm{O}^{[+\mathrm{K}]}$ conhece.

\subsubsection{Quadro téorico}

Para sustentar a hipótese em torno da oposição $[+\mathrm{K}] /[-\mathrm{K}]$ no âmbito dos constituintes (pro)nominais, nosso ponto de partida são os desdobramentos da proposta de Chomsky (2008) em torno da noção de "herança de traços", segundo a qual os traços-f realizados no núcleo $\mathrm{T}(\mathrm{empo})$ são herdados do núcleo $\mathrm{C}$ (omplementizador). Dentro dessa proposta, a posição de Spec-T em línguas como o inglês só é criada após $\mathrm{C}$ se concatenar ao TP e transferir seus traços para T. As representações em (47a) e (47b) mostram os pontos derivacionais respectivamente antes e depois da criação de Spec-T em uma construção do tipo The girl saw John. Em (47a), os traços-f não valorados (uf ) em C são transferidos para T, estabelecendo concordância (valoração via probe-goal) com o DP the girl em Spec- $v$. Somente após esse passo é que a posição de Spec-T é criada, como ilustrado em (47b), para abrigar o DP.

47) a.

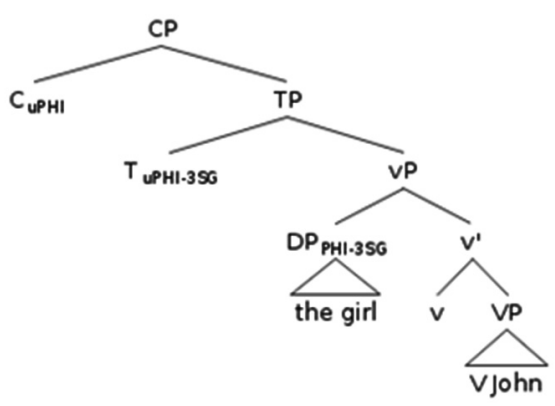

b.

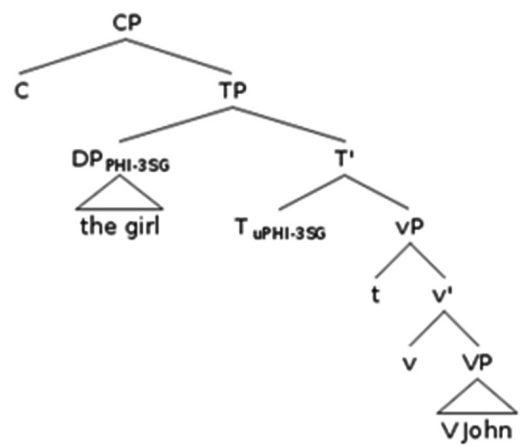

A partir dessa proposta, Avelar \& Galves (2011) propõem que o PB se difere de línguas como o inglês e das demais línguas românicas (aí incluído o português europeu - PE) pelo fato de Spec-T ser criado antes da concatenação de C a TP. 
Esse contraste pode ser visualizado em (48a) e (48b) a seguir, correspondendo respectivamente ao PE (ou a línguas como o inglês) e ao PB. A principal diferença entre as duas estruturas é que, quando $\mathrm{C}$ se concatena a TP, a posição de Spec-T não se encontra projetada em $\mathrm{PE}$, ao contrário do que ocorre em $\mathrm{PB}$, em que essa posição já se encontra preenchida (no caso, por um DP). Nos termos de Holmberg (2010), esse contraste incide sobre o estatuto de $\mathrm{f}$-(in)dependência do EPP de T: enquanto no PB o EPP é f-independente (ou seja, Spec-T é criado sem a ação de traços-f, podendo abrigar elementos que não concordam com os traços- $f$ a serem herdados por T), no PE o EPP é f-dependente (criado pela ação de traços$-f$, abrigando necessariamente elementos que devem concordar com os traços- $f$ herdados por $\mathrm{T})$.

48)

a. Português Europeu

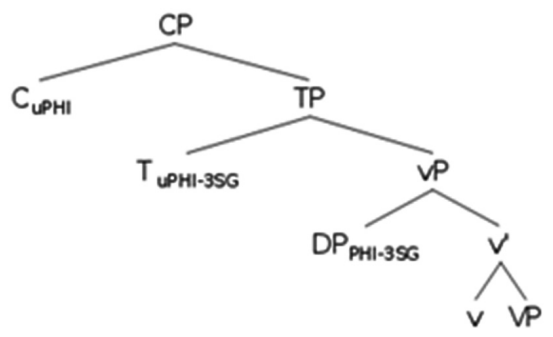

b. Português Brasileiro

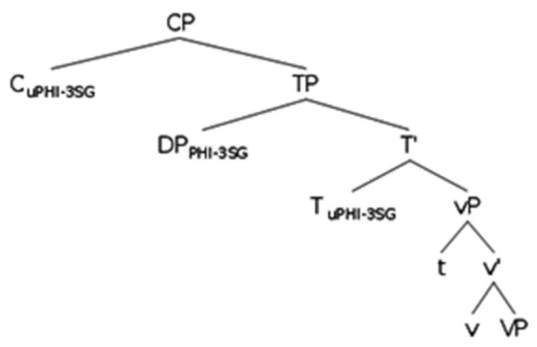

Nas próximas seções, vamos mostrar como esses pressupostos podem ser explorados para sustentar a hipótese em torno da oposição entre $[+\mathrm{K}]$ e $[-\mathrm{K}]$ no sistema pronominal do $\mathrm{PB}$, bem como expor algumas previsões e evidências em torno dessa hipótese.

\subsubsection{Previsões e evidências}

\subsubsection{Pronome oblíquo na posição de sujeito de orações infinitivas}

Os pressupostos apresentados na seção anterior, combinados com a hipótese de que os constituintes nominais do $\mathrm{PB}$ podem ser $[+\mathrm{K}]$ ou $[-\mathrm{K}]$, permitem encaminhar uma explicação para o contraste entre o PB e PE exemplificado em (49) a seguir: no PB, a forma oblíqua mim pode alternar com a forma nominativa eu na posição de sujeito de orações infinitivas introduzidas pela preposição pra; no PE, em contraste, apenas a forma nominativa pode ocorrer em tal posição.

49) PB: O caderno pra mim/eu fazer anotações sumiu.

PE: O caderno pra $e u$ fazer anotações sumiu. 
Esse contraste entre PE e PB pode ser explicado pela condição de f-(in)dependência do $\mathrm{EPP}_{\mathrm{T}}$ aliada ao estatuto $[+/-\mathrm{K}]$ das formas pronominais. A derivação das construções em (49) no PB vem ilustrada em (50) e (51), para os casos respectivamente com mim e $e u$, com a preposição pra sendo identificada como o núcleo da projeção CP. Dada a condição de f-independência do $\mathrm{EPP}_{\mathrm{T}}$, a forma pronominal de primeira pessoa do singular (1SG), que se realizará como mim ou $e u$, ocupa a posição de Spec-T antes da entrada de C na estrutura e, por extensão, antes dos traços $u$ f serem transferidos para T. Tendo em vista a possibilidade de o pronome ser $[+\mathrm{K}]$ ou $[-\mathrm{K}]$, a variação na forma pronominal pode ser explicada da seguinte forma: quando 1SG é [+K], como na representação em (50), os traços $u \mathrm{f}$ da preposição estabelecem concordância com o pronome, que então tem seu Caso valorado como oblíquo e é realizado como mim, a forma oblíqua da primeira pessoa do singular; quando $1 \mathrm{SG}$ é [-K], como em (51), o preposição não pode estabelecer concordância com o pronome, que é realizado na forma do Caso default (o nominativo).

50) $\left[_{\mathrm{CP}} \operatorname{pra}\left[_{\mathrm{TP}} 1 \mathrm{SG}^{[+\mathrm{K}: \mathrm{OBL}]}(=\operatorname{mim})\left[_{\mathrm{T}}, \mathrm{T}\left[_{v \text {-VP }}\right.\right.\right.\right.$ t ficar feliz $\left.\left.\left.]\right]\right]\right]$

51) $\left[_{\mathrm{CP}}\right.$ pra $\left[_{\mathrm{TP}} 1 \mathrm{SG}^{[-\mathrm{K}]}(=\mathrm{eu})\left[_{\mathrm{T}}, \mathrm{T}\left[_{\nu \text {-VP }} \mathrm{t}\right.\right.\right.$ ficar feliz $\left.\left.\left.]\right]\right]\right]$

Em PE, a situação é diferente, uma vez que Spec-T só é criado após a entrada de $\mathrm{C}$ (a preposição pra) na estrutura. A configuração na qual o Caso do pronome $[+\mathrm{K}]$ é valorado está esboçada em $(52)$ a seguir: os traços $u$ f só detectam o pronome, que se encontra em Spec- $v$, depois de serem transferidos para T; nessa situação, o Caso atribuído ao pronome é necessariamente o nominativo, uma vez que a atribuição casual se dá a partir de T, e não de C.

52) $\left[_{\mathrm{CP}} \operatorname{pra}\left[_{\mathrm{TP}} \mathrm{T}\left[{ }_{\mathrm{v}-\mathrm{VP}} 1 \mathrm{SG}{ }^{[+\mathrm{K}: \mathrm{NOM}]}(=\mathrm{eu})\right.\right.\right.$ ficar feliz $\left.\left.]\right]\right]$

As construções em (53) a seguir, que mostram orações infinitivas introduzidas pela preposição $d e$, reforçam essa análise: no $\mathrm{PB}$, a forma nominativa $e u$, mas não a forma oblíqua mim, é admitida em infinitivas antecedidas por de; no PE, nenhuma forma (pro)nominal é licenciada em infinitivas desse tipo.

53) a. PB: O caderno d'eu / " de mim / da Maria / de fazer anotações sumiu. b. PE: O caderno de ("eu/"mim/"a Maria) fazer anotações sumiu.

O contraste em (53) pode ser explicado se assumirmos que o item de, em contextos desse tipo, não é atribuidor de Caso (ou, em termos minimalistas, não é portador de traços- $u \mathrm{f}$ ); por consequência, apenas constituintes (pro)nominais [-K] podem ocorrer na posição de sujeito das orações infinitivas introduzidas por essa preposição. No que tange aos fatos do $\mathrm{PB}$, exemplificados em (53a), o pronome oblíquo mim é rejeitado por ser sempre $[+\mathrm{K}]$, ao contrário de eu e a Maria, 
que podem apresentar uma versão [-K]. Quanto aos fatos do PE, exemplificados em (53b), nenhum elemento é admitido na posição de sujeito da oração infinitiva pelo fato de essa língua não dispor de versões [-K] de constituintes (pro)nominais.

\subsubsection{Concordância variável e reduplicação pronominal}

A variação na concordância sujeito-verbo atestada no PB coloquial, exemplificada em (54) a seguir, também pode ser um reflexo da presença/ausência do traço de Caso em DPs na posição de sujeito. Se os elementos (pro)nominais podem ser $[+\mathrm{K}]$ ou $[-\mathrm{K}]$, essa variação é esperada: diferentemente dos elementos $[+\mathrm{K}]$, os [-K] não podem estabelecer concordância com os traços $u \mathrm{f}$ de $\mathrm{T}$, tendo em vista que, dentro dos pressupostos aqui assumidos, é a presença de um traço de Caso não valorado que habilita um DP a estabelecer relação de concordância com traços $u \mathrm{f}$.

54) a. Os menino(s) jantou / jantaram.

b. As criança(s) brincava / brincavam na varanda.

c. Naquele restaurante pro $_{\text {generico(3PL) }}$ faz / fazem pratos maravilhosos.

Uma consequência atrelada a essa análise está na implicação de que, se constituintes (pro)nominais podem ser $[+\mathrm{K}]$ ou $[-\mathrm{K}]$, o complexo $\mathrm{C}-\mathrm{T}$ pode ou não ter traços-uf para serem valorados. Embora não nos seja claro como essa opcionalidade referente aos traços- $u f$ possa ser tecnicamente implementada (tendo em vista, principalmente, a realização da flexão verbal na terceira pessoa do singular nos casos de não concordância), essa ideia pode lançar luz sobre propriedades observadas no complexo $v$-V do PB. De acordo com Chomsky (2008), todo núcleo de fase pode transferir traços-uf (bem como outros traços relevantes) para seu complemento, o que implica assumir que a herança de traços- $u$ f se opera não apenas nos domínios de $\mathrm{C}$ e $\mathrm{T}$, mas também nos de $v$ e V - com o segundo recebendo traços- $u$ f do primeiro. Se, de fato, houver um paralelismo entre C-T e $v$-V no que diz respeito à disposição dos traços- $u f$, é igualmente esperado que, frente à oposição $[+\mathrm{K}] /[-\mathrm{K}]$, o complexo $v$-V pode ou não ter traços- $u$ f para serem valorados. As construções do $\mathrm{PB}$ em que um pronome [-K] é licenciado na posição do objeto apresentadas em (46 a,b,c) são casos para os quais é necessário assumir que $v$ não dispõe de traços- $u$ f nessas condições.

Essa ideia pode lançar luz sobre a derivação de construções como em (55) a seguir, em que uma forma pronominal oblíqua co-ocorre com uma forma nominativa na expressão do objeto direto. Podemos considerar que a reduplicação pronominal resulta de uma situação em que, embora o complexo $v$-V disponha de 
traços- $u$ f a serem valorados, um pronome [-K] é inserido na posição de objeto; em tal situação, um pronome [+K] é requerido para "salvar" a construção, estabelecendo concordância com os traços- $u \mathrm{f}$ de $v$-V, como esboçado na representação.

55) a. Me deixa eu em paz!

b. Ele sempre me beija eu no rosto.

c. "me leva eu junto com você"

d. "te procurei você no armário"

e. "eu sei que te machuquei você"

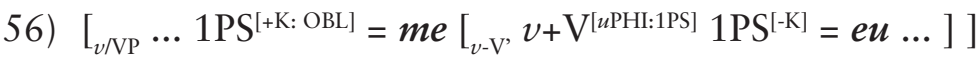

Casos de duplicação pronominal também são largamente atestados em posição de sujeito no PB (cf. Kato 1999), como em (57) a seguir, o que também pode ser o resultado da situação em que C-T dispõe de traços- $u$ f a serem valorados, com a versão $[+\mathrm{K}]$ do pronome satisfazendo a esse requerimento.

57) a. Ela disse que você, você não sabe o que está falando.

b. Ouvi dizer que ele, ele não é um bom médico.

c. Parece que eu, eu estou ficando doente.

\subsubsection{Ausência vs. presença da preposição junto a constituintes dativos}

Outro fato que pode ser abarcado pela oposição $[+\mathrm{K}] /[-\mathrm{K}]$ diz respeito à alternância entre ausência vs. presença de preposição junto a constituintes dativos, ilustrada pelo exemplo em (58) a seguir. Como indicado em (59), a ausência da preposição pode ser explicada pela ocorrência de um constituinte nominal [-K], em oposição à ocorrência de constituinte $[+\mathrm{K}]$, que requer a presença da preposição para valorar o seu traço de Caso.

58) a. "Quando perguntamos os alunos que nos acompanharam onde estavam os edifícios principais do governo, eles eram vagos"

b. Quanto perguntamos pros/aos alunos...

59) (a. Perguntamos [os alunos $]^{[-\mathrm{K}]}$

b. Perguntamos pr[os alunos $]^{[+\mathrm{K}: \mathrm{OBL}]}$

\subsection{CONSIDERAC̣ÕES FINAIS}

Neste capítulo, abordamos tópicos cruciais para a compreensão da especificidade do português brasileiro: a variação no uso da $2^{\text {a }}$ e $3^{\text {a }}$ pessoa para se referir 
ao destinatário do discurso, a variação entre $1^{\text {a }}$ e $3^{\text {a }}$ pessoa verbal na concordância com a primeira pessoa expressa por um pronome ou um sujeito nulo, a variação entre pronomes (fortes) invariáveis quanto ao caso morfológico e pronomes (clíticos) marcados para o caso. Todos esses fenômenos distinguem fortemente o PB das outras línguas românicas, inclusive do português europeu. A questão se coloca de definir mais precisamente os limites dessa variação, bem como sua fonte. Os itens 6.2 e 2.3 mostram que ela se constitui historicamente, tanto na vertente escrita da língua quanto nas suas fontes orais ainda próximas do intenso fenômeno de contato que caracteriza a gênese do português no Brasil, cujos efeitos mais fortes são ainda visíveis nas comunidades afro-brasileiras, como a de Helvécia. Já os fenômenos relatados no item 6.4 representam uma variação sincrônica moderna, cujo meio é ao mesmo tempo a sociedade e o indivíduo. Surge então a pergunta sobre os mecanismos subjacentes a essa variação: será o embate da "gramática dos letrados" (KATO, 2005) com o vernacular marcado pelo contato, constituindo o que Kroch (1994) chama de competição de gramáticas? Ou será uma variação dentro duma gramática única, a gramática que se constituiu a partir das condições sócio-históricas de emergência do PB? Não é o objetivo deste texto responder a essa pergunta. O item 6.4, porém, encaminha para a segunda hipótese quando argumenta que as expressões nominais podem entrar na derivação com ou sem traço de caso. Desse ponto de vista, a diferença dialetal de ordem social ou geográfica encontrada no Brasil seria uma variação na escolha das formas produzidas por uma gramática só e não na escolha de gramáticas diferentes. Deixamos esta questão aberta para futuras pesquisas. A nossa contribuição aqui pretendida é mostrar que a variação na sintaxe pronominal é diacrônica e sincronicamente constitutiva do português no Brasil. Do ponto de vista da morfologia, tal variação se explica pelas noções de composicionalidade e subespecificação de traços. Do ponto de vista da sintaxe, a noção de caso abstrato associada às propriedades das categorias funcionais deriva os fenômenos observados. Nos dois casos, tudo leva a pensar que o forte contato linguístico desempenhou um papel essencial na reorganização morfossintática da língua.

\section{REFERÊNCIAS}

BAXTER, A. Creole-like features in the verb system of an Afro-Brazilian Variety of Portuguese. In: SPEAS, A.K.; WINFORD, D. (Ed.). The Structure and Status of Pidgins and Creoles. Amsterdam: John Benjamins, 1997. p. 265-288, BEJÁR, S. Phi-syntax: a theory of agreement. 2003. Tese (Doutorado) - University of Toronto, Toronto, 2003.

BEJÁR, S. Conditions on Phi-Agree. In: HARBOUR, D; ADGER, D.; BEJAR, S. (Ed.). Phi-Theory: Phi-Features Across Modules and Interfaces. New York: Oxford University Press, 2008. 
BORER, H. Parametric Syntax. Dordrecht: Foris, 1983.

CARDINALETTI, A; M. STARKE. The typology of structural deficiency. In: VAN RIEMSDIJK, H. (Ed.). Clitics and other functional categories in European languages. Berlin: Mouton de Gruyter, 1999. p. 145-233.

CARVALHO, D. S. A estrutura interna dos pronomes pessoais em português brasileiro. Tese (Doutorado) - Universidade Federal de Alagoas, 2008.

CARVALHO, D. S. Sincretismo, subespecificação de traços e a sintaxe de gênero em uma comunidade do português afro-brasileiro: um estudo de caso. Papia, v. 21, n. 1, p. 83-97, 2011.

CHOMSKY, N. The Minimalist Program. Cambridge: MIT Press, 1995. . Minimalist Inquiries: the Framework. Cambridge: MITWPL, 1998. . Derivation by Phase. MIT Occasional Papers in Linguistics, n. 18. Cambridge: MIT Working Papers in Linguistics, 1999.

DÉCHAINE, R-M.; WITSCHKO, M. Decomposing pronouns. Linguistic Inquiry, v. 33, n. 3, p. 409-442, 2002.

DUARTE, M. E. L. A perda do princípio 'Evite Pronome' no português brasileiro. Tese (Doutorado) - Universidade Estadual de Campinas, Campinas, 1995.

FRAMPTON, J.; GUTMANN, S. Agreement is feature sharing. Boston: Northeastern University, 2000.

HALLE, M.; MARANTZ, A. Distributed morphology and the pieces of inflection. In: HALE, K.; KEYSER, S. J. (Ed.). The view from building 20. Cambridge: MIT Press, 1993. p. 111-176.

HARLEY, H.; RITTER, E. Person and number in pronouns: a feature-geometric analysis. Language, n. 78, p. 482-526, 2002.

HOLMBERG, A. Is there a little pro? Evidence from Finnish. Linguistic Inquiry, v. 36, n. 4, p. 533-564, 2005.

HUANG, C-T. J. On the distribution and reference of empty pronouns. Linguistic Inquiry, v. 12, p. 531-574, 1984.

HUANG, C-T. J. Pro-drop in Chinese. In: JAEGGLI, O.; SAFIR, K. (Ed.). The null subject parameter. Dordrecht: Kluwer, 1989.

JAEGGLI, O.; SAFIR, K. (Ed.) The null subject parameter. Dordrecht: Kluwer, 1989.

KATO, M. Strong pronouns and weak pronominals in the null subject paramente.

Probus, v. 11, n. 1, p. 1-37, 1999.

KATO, M. A gramática do letrado. In: MARQUES, M. A.; KOLLER, E.; TEIXEIRA, J.; LEMOS, A. S. (Org.). Ciências da linguagem: trinta anos de investigação e ensino. Braga: CEHUM, 2005.

LONGOBARDI, G. Reference and proper names. Linguistic Inquiry, v. 25, p. 609-665, 1994. LOPES, C. R. S.; CAVALCANTE, S. R. O. A cronologia do voceamento no português brasileiro: expansão de você-sujeito e retenção do clítico-te. Revista Lingüistica, Madrid, v. 25, p. 30-65, 2011. 
LUCCHESI, D. A realização do sujeito pronominal. In: LUCCHESI, D.; BAXTER, A.; RIBEIRO, I. (Org.). O Português Afro-Brasileiro. Salvador: EDUFBA, 2009. p. 167-183. LUCCHESI, D.; BAXTER, A.; RIBEIRO, I. (Org.). O Português Afro-Brasileiro. Salvador: EDUFBA, 2009.

MACCLOSKEY, J.; HALE, K. On the syntax of person number inflection in Modern Irish. Natural Language and Linguistic Theory, v. 2, p. 487-533, 1984.

MAGALHÃES, T. M. V. As pessoas do discurso na produção de sujeitos nulos na aquisição do Português Brasileiro e do Português Europeu. Handout apresentado no V Encontro Nacional de Língua Falada e Escrita - ELFE. Maceió, 2006.

MOURA, D. (Org.). Resquícios de Palmares: o que a comunidade quilombola nos diz. Maceió: Edufal, 2009.

OLIVEIRA, T. L. Entre o linguístico e o social: complementos dativos de $2^{a}$ pessoa em cartas cariocas (1880-1980). Dissertação (Mestrado em Língua Portuguesa) Universidade Federal do Rio de Janeiro, Rio de Janeiro, 2014.

PERINI, Mário A. Gramática do português brasileiro. São Paulo: Parábola, 2010. PERINI, Mário A. O surgimento do sistema possessivo do português coloquial: uma interpretação funcional. Revista DELTA, v. 1, n. 1-2, p. 1-16, 1985.

RIBEIRO, I. O sujeito nulo referencial no português popular brasileiro - século XIX. In: TORRES MORAIS, M. A. C. R.; ANDRADE, L. C. V. O. (Org.). História do português paulista. Campinas, SP: Unicamp/Publicações IEL, 2009, p. 83-98.

RIBEIRO, I. O sistema de finitude e de referencialidade de uma falante afro-brasileira idosa. Handout apresentado no V Encontro da ABECS. Salvador, 2010.

RIZZI, L. Null objects in Italian and the theory of pro. Linguistic Inquiry, v. 17, n. 3, p. 501-557, 1986.

ROBERTS, I. Creoles, markedness and the Language Bioprogram Hypothesis. Estudos Linguísticos e Literários, Salvador, n. 19, p. 11-24, 1997.

ROBERTS, I. A deletion analysis of null subjects: French as a case study. Cambridge: University of Cambridge, 2007.

RUMEU, M. C. B. Lingua e sociedade: a história do pronome "você" no português brasileiro. Rio de Janeiro: Ítaca, 2013.

SCHERRE, M. M. P. et al. Usos dos pronomes você e tu no português brasileiro. In: II SILMEP, Portugal. Anais... Portugal: Ed. da Universidade de Évora, 2009.

SOUZA, J. P. F. de. Mapeando a entrada do Você no quadro pronominal: análise de cartas familiares dos séculos XIX-XX. Dissertação (Mestrado em Língua Portuguesa) Universidade Federal do Rio de Janeiro, Rio de Janeiro, 2012.

SOUZA, C. D. Eu te amo, Eu the adoro, Eu quero você: a variação das formas acusativas de $2^{a}$ pessoa em cartas pessoais (1880-1980). Dissertação (Mestrado em Língua Portuguesa) - Rio de Janeiro: Universidade Federal do Rio de Janeiro, 2014. SPEAS, M. Economy, agreement and the representation of null arguments. In: ACKEMA, P. et al. (Ed.). Agreement and argument structure. Oxford: OUP, 2004. 
